\title{
O Diálogo Humanizante Como Expressão De CuIdado
}

\author{
Fernando Bento ${ }^{1}$ \\ Universidade de Évora - CIDEHUSI
}

\begin{abstract}
Resumo
Enquanto construção de singularidades dialógicas difundidas na expressão da alegria e na manifestação do cuidado, é importante ressalvar a necessária congruência entre o pensamento e a ação como o verdadeiro jogo de afetos que constitui a humanidade. Assim, pretende-se esclarecer a posição de Matthew Lipman face a um re-nascimento significativo de uma ética do preferível como realização de uma satisfação que valoriza o hábito reflexivo, sobre si, sobre os outros e sobre o mundo, animados ou inanimados, ou seja, humanos e não-humanos, e, uma re-criação significante de uma experiência de vivência política como definição de um sentido de comunidade, e ainda, de relação humanizante, emocionalmente competente, fundada na tentativa de re-construir cooperativamente uma sociedade generosa, educadora e democrática. Eis um dos fundamentos da Comunidade de Investigação, que nomeamos, não apenas uma comunidade onde a atitude dialógica da comunicação permite reforçar o sentido de comunidade mas também onde reina a filosofia enquanto método e conteúdo investigativos, uma Comunidade Dialógica de Investigação Filosófica.
\end{abstract}

Palavras-chave: comunidade de investigação; diálogo; generosidade; cuidado

\section{THE HUMANIZING DIALOGUE AS CAREFUL EXPRESSION}

\begin{abstract}
While building dialogic singularities widespread in the expression of joy and manifestation of care, it is important to note the necessary consistency between thought and action as the real game of affects that constitutes humanity. Thus, it is intended to clarify the position of Matthew Lipman in face of a significant re-birth of an ethics of the preferable as conducting a satisfaction that values reflective habit, about themselves, about the others and about the world, animates or inanimate, which means, human and nothuman, and, of a significant re-creation of an experience of a political living as defining a sense of community, a humanizing relationship, in other words, emotionally competent, founded in an attempt to re-build cooperatively a generous, educative and democratic society. There it is one of the major cornerstones of the Community of Inquiry, not just a community where the dialogic attitude helps to strengthen the sense of cooperation but also ruled by philosophy as a method and investigative content, which we name as a Dialogic Community of Philosophical Inquiry.
\end{abstract}

Keywords: community of inquiry; dialogue; generosity; caring.

\footnotetext{
${ }^{1}$ E-mail: benitoliis@gmail.com
} 
o diálogo humanizante como expressão de cuidado

\section{EL DIALOGO HUMANIZANTE COMO EXPRESIÓN DE CUIDADO}

\section{Resumen}

En cuanto construcción de singularidades dialógicas difundidas en la expresión de la alegría y en la manifestación del cuidado, es importante tener en cuenta la necesaria congruencia entre el pensamiento y la acción como el verdadero juego de afectos que constituye la humanidad. Así se pretende aclarara la posición de Mathew Lipman que hace un renacimiento significativo de una ética de lo preferible como realización de una satisfacción que valoriza el habito reflexivo sobre si, sobre los otros y sobre el mundo animado e inanimado, o sea sobre los humanos y los no humanos, y una recreación significante de una experiencia de vivencia política como definición de un sentido de comunidad, aún de relación humanizante, emocionalmente competente fundada en el intento de reconstruir cooperativamente una sociedad generosa, educadora y democrática. Este es uno de los fundamentos de la Comunidad de Indagación que nominamos, no sólo como una comunidad donde la actitud dialógica de la comunicación permite reforzar el sentido de comunidad, sino también donde reina la filosofía en tanto método y contenido investigativos, una Comunidad Dialógica de Investigación Filosófica.

Palabras clave: comunidad de investigación; diálogo; generosidad; cuidado. 


\section{O DiÁlogo HuMANIZANTE COMO EXPRESSÃo De CUIDADO}

Quando Cícero evoca a figura de Sócrates, nominando-o como aquele que fez vir a filosofia do céu à terra, exprimiu exatamente o carácter da investigação inculcado por este pensador na tradição filosófica, que resgatado por Lipman enforma o suporte teórico da sua metodologia pedagógica. Esta tem por objeto, exclusivamente, o homem e o seu mundo, isto é, um mundo que é também uma comunidade na qual se inscreve, persevera, cresce, vive e convive.

O crivo fundamental da formação deste carácter investigativo é tentar pôr a claro o homem, cada ser-sujeito individual, consigo mesmo, encaminhando-o ao autoconhecimento e ao re-conhecimento de si mesmo, das suas competências e dos seus limites, e consciencializar-se das possibilidades de adquirir as habilidades cognitivas, emocionais, sociais e políticas que o permitirão crescer intelectualmente e viver generosamente com os outros seres, tornando-o em e tomando o Outro como sujeito-pessoa na sua condição essencial de uma existência profícua e feliz.

Este exercício filosofante e incessante sobre si próprio, de si próprio em relação aos outros e dos outros em relação a si próprio, formula o intuito primário da formação holística ${ }^{2}$ promovida por Lipman em toda a sua obra filosófica. E enuncia que, esta arte de pesquisa e investigação comum define o homem, neste caso, o sujeito-criança, que não pode ver claro apenas por si só, mas que precisa sempre do outro para que juntos construam a sua singularidade, aprimorando, simultaneamente, o sentido de comunidade.

A investigação de que se ocupa a criança não pode começar e acabar no círculo fechado da individualidade, pelo contrário, pode até partir de si mas fecunda-se prioritariamente num dialogar contínuo consigo mesmo e com os outros, seja qual for a natureza com que se nos apresenta. Este vínculo ${ }^{3}$ (LIPMAN, 1990, p. 76), comprometido com os outros, só pode progredir com a interajuda

\footnotetext{
2 Admirar e entender a natureza do ser humano conectada ao contexto natural e social onde se inscreve e participa. Nesta perspetiva, cada sujeito é encarado como multiplicidade na unidade, e, ao mesmo tempo, unidade da multiplicidade.

3 "A filosofia pressupõe um compromisso com a investigação aberta."
} 
o diálogo humanizante como expressão de cuidado

testemunhando de que o valor do indivíduo só pode ser compreendido e realizado em "relação". Este "entre" buberiano, este acontecimento de um evento relacional, garante a cada um a liberdade e a autenticidade do exercício de busca e descoberta de si próprio, num sentido dialógico que estimula o cuidado que se promove a si mesmo sobre si com o intuito humanizante de ser também promovido com e sobre os outros.

Martin Buber (2009), lido por Lipman (1995, p. 35), elucida-nos sobre este caminho afirmando que:

[...] a comunidade em evolução é o estar não-mais-um-ao-lado-do-outro, mas estar um-com-o-outro, de uma multidão de pessoas que, embora se movimentem juntas em relação a um objetivo, experienciam em todo o lugar um dirigir-se-um-ao-outro, um face-a-face dinâmico, um fluir do Eu para o $\mathrm{Tu}$; a comunidade existe onde a comunidade acontece.

Nas palavras redigidas por Ann Sharp (s/d, p. 3), esta intencionalidade mostrada por Buber (2009) está patente como um apelo motivador à sua consumação:

[...] há pois uma evidente preocupação no grupo, não só pelos procedimentos lógicos, mas também pelo desenvolvimento e pelo crescimento de cada membro da comunidade. Esta preocupação supõe a predisposição em estar aberto às sugestões dos outros e a mudar os nossos pontos de vista e prioridades se assim ajudarem os outros. Em sentido próprio, preocupar-se significa ter boa vontade por mudar ou reconhecer-se afetado pelo que os outros proferem. Esta preocupação é essencial para que se dê o diálogo. Mas também é essencial para que se desenrole a confiança. [...] A confiança, por outro lado, é uma condição prévia para o crescimento da autonomia e da autoestima de cada um dos membros participantes.

Este apelo não significa que se renuncie à própria identidade e ao direito de pensar-se por si mesmo autonomamente; pelo contrário, participar numa comunidade de investigação e poder dispor de um espelho onde estão refletidos os nossos argumentos permitir-nos-á evitar cair no erro de nos equivocarmos sobre opiniões injustificadas, sem fundamento ou insuficientes, saindo mais fortes e mais seguros das nossas ideias, convicções ou posições. É aqui que o verdadeiro sentido de comunidade acontece. 
Sem descurar o imaginário poético infantil, que subsidia o desenvolvimento integral ${ }^{4}$ do sujeito-criança, este espaço dialógico confere um sentido de comunicação sobre esse papel de integridade, identidade e autoria não individualistas, da criança consigo mesma, em disciplina, por forma a tornar-se crítica sobre o seu pensar e pró-ativa no seu devir sujeito-criança-pessoa no jogo educativo lipmaniano. Este cuidado cuidadoso imprimido no diálogo comunicativo é uma preciosidade sobre o desenvolvimento das destrezas intelectuais bem como no fortalecimento do carácter (ou estilo) que perfaz a relação íntima ${ }^{5}$, ou seja, um tornar-me presente na pessoa que eu sou, que eu sei ser, sei saber ser e sei saber aprender a ser.

$\mathrm{Na}$ mesma linha, George Snyders defende estas valências intracomunicativa e intercomunicativa - como atos de extrema importância. Na sua obra Alunos Felizes Snyders (1996, p. 63-64) afirma que:

[...] parece que ordinariamente a criança vive a comunicação como coisa evidente e garantida; ela sente que há um terreno comum entre os seres, uma coexistência pacífica; a proximidade leva mesmo à indivisão, a vida alheia e a sua participam da mesma história. Em seguida, ocorre a descoberta da distância entre os seres, a pluralidade das perspetivas, muros, cisões, solidão, mas como compensação capital cada um terá um ponto de vista original.

Porém, aquilo que parece irremediavelmente um fosso dentro desta dinâmica, não o é. Ainda na mesma obra, Snyders (1996, p. 64) cita Merleau-Ponty (1964) e acrescenta que:

[...] não se pode mais separar absolutamente os papéis... amar é viver pelo menos em intenção a vida do outro. $\mathrm{O}$ amor tira de mim mesmo e institui uma mistura de mim e do outro. (...) Essa confiante comunicação com o outro em harmonia com o sentimento de cada vida em particular [...] não é impossível e constitui um notável exemplo da unidade progressiva de uma vida humana.

Suportados pelo pensamento buberiano, reconhecemos nesta autoformação afetuosa, enquanto núcleo essencial da atividade educadora pressuposta na relação dialógica, a própria essência humana. Nela se encontra não só a orientação

\footnotetext{
4 Tomar consciência das relações parte-todo, formuladas sob uma harmonia da inteligência e da totalidade da sua vida. Esta integridade baseia-se numa integridade da práxis, ou seja, a existência coerente entre os nossos sentimentos, pensamentos e ações. Retratando, assim, uma compatibilidade e sintonia entre cada ação individual e a linha geral da nossa conduta.

${ }^{5}$ De convite.
} 
o diálogo humanizante como expressão de cuidado

para a realização da conduta moral, mas também a possibilidade de pensar a singularidade do vivido que se expressa como realização e satisfação na praxis existencial.

É possível reconhecer as diversas situações face às quais o sujeito-criança deve posicionar-se, situações em que se evidencia a necessária alteridade e o exercício da cidadania, como propósitos de aceitação de como ele é e como poderá vir a ser. Podemos assim afirmar que o que justifica e torna indispensável a atitude dialógica do diálogo é a necessidade que temos de re-construção permanente de uma comunidade altruísta radicada no bem-estar, desafiando a extensão da comunidade aos mecanismos da vida.

Destes, advimos que algo nos impele para a compreensão da evolução natural da atitude altruísta tomada no lugar de bem-estar com o intuito de juntos conseguirmos atingir a suprema felicidade que tanto almejamos, essencial para quem busca um lugar seguro e confortável para aprender a ser, a pensar, a sentir, a viver e a conviver. Neste encontro onde nos doamos ao Outro, qualquer que seja a sua natureza, razão e coração conjugam-se sempre que se manifestam empaticamente num exercício moderado pela constância da alteridadé ${ }^{6}$

Esta autoconsciencialização de que naturalmente a todos confluímos e divergimos de um mesmo centro nevrálgico vital e que todos temos uma missão que se coaduna e coordena com a mesma de todos os demais é o culminar de todo um sentido político que imprimimos à nossa vida desde tenra idade até à morte. $\mathrm{O}$ desejo da democratização existencial sobre a nossa condição digna e condigna permite-nos superar a justiça e a equidade transformando-as em generosidade e pessoalidade vivenciada, sentida e projetada.

Esta tónica expressiva de um exercício político pela participação num agir que só encontra o seu sentido a partir da atividade do pensamento pode ser tomado como pressuposto na disposição do ser-criança como um dinamismo

\footnotetext{
6 A tarefa de romper com as dicotomias entre o homem e os demais, entre esferas do funcionamento do homem no mundo, possibilita que se exercite a noção de alteridade, como constituinte essencial do sujeito pelo respeito fundamental através da tomada de consciência de que qualquer ser predica, ontologicamente, um do outro e um com o outro, num feixe de relações cunhadas de cumplicidade, reciprocidade e generosidade.
} 
desejado sobre a necessidade e a capacidade de aprender, um processo de recriação da experiência humana pensada, sentida e vivida. O próprio princípio de continuidade da vida humana revela uma relação intrínseca entre o individual, o social e o educacional, pois sabemos que o indivíduo e a sociedade, ou melhor, a pessoa e a comunidade se educam mutuamente.

Esta disposição educadora da Comunidade de Investigação é suportada por um cuidado cuidante que projeta a criança numa dimensão ética e política enraizada em valores humanos suportados pela investigação cooperativa, garantindo a liberdade de expressão, a aceitação da diferença como instrumento de perspetiva, de alternativa divergente, a atenção e a escuta manifesta pelo outro que se quer ser presença, a experiência comunicada e emocionalmente competente.

É na presença que o homem constrói o seu modo de ser, a sua existência, a sua história. Esta condição refere-se ao movimento de aproximação, ao dinamismo da exteriorização de uma demanda de operacionalização da sua essência desejante. No fundo, nesta projeção conflui toda a potencialidade humana que pode ser desenvolvida e encorajada pelo próprio ambiente educacional que rege a Comunidade de Investigação e a que damos o nome de diálogo humanizante, pois permite situar a aprendizagem formativa do homem a partir do compromisso com o mundo no qual vivemos. Esta força motriz do pensamento investigativo e de instância deliberativa libera-nos e nutre-nos de amor por aproximação, reciprocidade e alteridade.

É a especificidade dialógica do diálogo que confere ao sujeito-criança-pessoa a abertura imediata ao Outro, de uma forma espontânea e autêntica de relação na escolha e na afirmação dele não como um objeto mas sempre como mais um sujeito. Esta generosidade 7 , este dar-se doando-se, sem pretensões ou preconceitos, acompanhada pela coragem ${ }^{8}$ (COMTE-SPONVILLE, 1995, p. 56-57) de manifestar

\footnotetext{
7 "Um desejo pelo qual um indivíduo, partindo apenas dos ditames da razão, se esforça por assistir os outros homens e estabelecer laços de amizade entre eles e a sua pessoa. [...] As ações que [...] visam igualmente a utilidade dos outros, à generosidade." In Parte III, Escólio da Proposição 59.

8 "[...] podemos considerar que a ação corajosa manifestará maior domínio, dignidade, liberdade, qualidades que são, essas sim, moralmente significativas e que transmitirão à coragem, de maneira como que retroativa, algo do seu valor: não sendo sempre moral na sua essência, a coragem é, por certo, aquilo sem o qual toda a
} 
o diálogo humanizante como expressão de cuidado

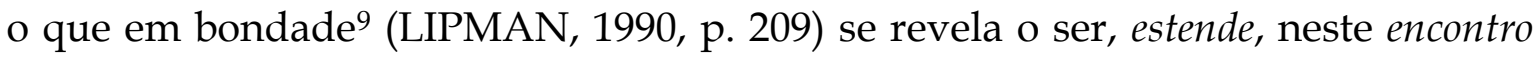
humanizante de expressão de cuidado, uma dupla condição: cuidadosa consigo mesma e cuidante para com o Outro, acalentando o mais legítimo direito de viver assegurando a vida e a existência de todos os seres que connosco co-habitam neste território universal, que é o planeta.

Este respeito incondicional funciona como um ímpeto potencializado pela experiência co-partilhada pelo bem de cuidado cuidante daquilo que, para nós, é interessante e desejável, positivamente, em ato relacional. Ligado a este ponto, um dos fundamentos desta evolução/progresso do programa metodológico de Lipman mais que a simpatia, é a empatia ${ }^{10}$ (LIPMAN, 1990, p. 229), estado referente à capacidade de se colocar no lugar do outro, reintegrando um possível clima de confiança e segurança de uma humanidade que aspira à criação e recriação permanentes em cada sujeito-criança alheando-se do facto de expurgar o próximo de sentir-se parte do todo que é a Comunidade que, em si mesma, lhe confere valor, respeito, tolerância e afinidade. Assim, crê Lipman que, pragmaticamente, se aproximarão os legados humanos de cosmovisões distintas numa celebração de vidas esclarecidas e merecedoras.

Resultante desta disposição empática, tanto o que se cuida a si mesmo como o que cuida o outro, surge um segundo nascimento face à experiência vivenciada, radicada num interesse desejado e desejante, devido à provocação necessária sob as novas inquietações acerca da amplitude das suas mundividências, culminando num encontro dialógico que servirá de impulso recreativo para a preservação de uma tentativa de internalização ${ }^{11}$ por forma a projetar a assimilação interiormente e inteiramente daquilo que com os outros aprendemos em relação de modo a re-significar a nossa experiência, corrigindo-nos dos possíveis equívocos e esclarecendo as nossas ações éticas, políticas e sociais.

moral seria impossível ou sem efeito. [...] Esta coragem não é a ausência do medo: é a capacidade para vencêlo, sempre que aparece, graças a uma vontade mais forte, mais generosa."

9 "[...] deixar que as crianças sejam elas mesmas, isto é, naturalmente boas."

10 "Para que um programa de educação moral seja adequado, deve permitir à criança pensar racionalmente, desenvolver padrões de conduta construtiva, perceber os seus sentimentos pessoais e os dos outros, desenvolver uma sensibilidade para contextos interpessoais, e adquirir um senso de proporção em relação às suas próprias necessidades de aspirações em face das dos outros."

${ }^{11}$ Reprodução intrapsíquica do interpsíquico Vygostkyniana. 
Lipman, em O Pensar na Educação, evidencia que «o que a Comunidade de Investigação fornece é um núcleo que tanto representa como antecipa» (LIPMAN, 1995, p. 357), ou seja, está bem patente a intenção que o próprio grupo representa um tipo de sociedade co-operativa como uma projeção de uma possível sociedade que é uma comunidade destas comunidades.

Como tal, aferimos que a aprendizagem é um acionar da dimensão individual do sujeito-criança, sendo, porém, o conhecimento uma interlocução subjetiva, ou uma intersubjetividade, que se fortalece quando é construtiva e socializada, pois, quando esta familiarização acontece, enriquece cada participante cognitiva, afetiva e pessoalmente. Lipman define este estado como «aquisição de um comportamento característico da boa cidadania [...], considerar o bem da sociedade juntamente com o seu próprio bem pessoal.»(LIPMAN, 1995, p. 75).

Isto é, a atitude dialógica, suportada pelo imperativo naturado do cuidado, fruto de uma atmosfera nutritiva e proteica, perfaz da aprendizagem vivencial uma prática democrática, sensível ao contexto onde ocorre, penetrante no espaço e perdurável no tempo. De cada novo espanto/deslumbramento, de cada nova pergunta, de cada nova ideia, de cada nova palavra dita, escrita ou desenhada, nasce um novo mundo de variantes que não se confundem nem se anulam, mas caminham lado-a-lado com o mesmo propósito de tentar "passar de um estado de menor perfeição para um estado de maior perfeição"12. Tanto para quem se cuida como para quem a intencionalidade desse cuidado se remete.

A manifestação da tríade humana - sentir, pensar e atuar - assumida de sentido, presente no ouvir, no perguntar, no duvidar, enriquece-se pela reflexão tecida pelo pensamento cuidadoso e pela ação cuidante num processo de tradução e participação tomado como habilidades éticas e políticas de significado da vida para a vida, conduzido tanto sendo de mim para si, como de si para si, e mesmo de mim para com.

Os temas dos direitos e liberdades humanas por esta aprendizagem apresentados nascem e desenvolvem-se da partilha de pensamentos, sentimentos

\footnotetext{
12 Parte III, Demonstração da Proposição 21.
} 
o diálogo humanizante como expressão de cuidado

e ações, considerados a base de projetos corajosos, honestos e generosos que encantam a vida vivida quando se dispõem a aspirar à humanidade (paz), à liberdade e à democracia.

Se atendermos ao desejo das últimas palavras de Sócrates, no leito da sua morte, verificamos que o apelo ao homem e à sua circunstância estão presentes, num claro sinal de esperança, generosidade, cuidado ${ }^{13}$ e alegria $^{14}$ :

Se tiverdes cuidado com vós próprios, qualquer coisa que façais ser-me-á grata, bem como aos meus e a vós mesmos, ainda que agora não vos empenheis em nada. Mas se pelo contrário não vos preocupardes com vós próprios e não quiserdes viver de maneira conforme àquilo que agora e no passado vos tenho dito, fazer-me agora muitas e solenes promessas de nada servirá." (PLATÃO, 1987, 115b)

Portanto, Lipman apela para que sejamos dialogicamente dialogantes, cuidadosos e cuidantes, generosos e humanizantes e pensemos com rigor e vigor, com coragem e doçura ${ }^{15}$ (COMTE-SPONVILLE, 1995, p. 200) por forma a convivermos sob atitudes educadoras e democráticas, autênticas e genuínas, com intuito de desenvolvermos, juntos, ética e politicamente, o significado existencial que nos dignifica enquanto pessoas que somos sendo, promovido pelo desejante sentido de ser-sujeito e o preferível bem-estar comum, caracterizante de uma sociedade mais perfeita regida por um pensar mais útil, mais eficiente, mais complexo (multidimensional), ou seja, de ordem Superior'16 (LIPMAN, 1995, pp. 3640).

\section{Referências}

BUBER, M. Do Diálogo e do Dialógico. São Paulo: Perspetiva, 2009.

COMTE-SPONVILLE, A. Pequeno Tratado das Grandes Virtudes. Lisboa: Presença, 1995.

LIPMAN, M. A Filosofia vai à Escola. São Paulo: Summus Editorial, 1990.

O Pensar na Educação. Rio de Janeiro: Vozes, 1995.

PLATÃO. Fedon. Lisboa: Guimarães Editores, 1987.

\footnotetext{
${ }^{13}$ Rigor, carácter, personalidade, pessoalidade.

${ }^{14}$ Expressa na gratidão que Sócrates tem sobre os seus discípulos.

15 "A doçura remete-se ao real, à vida, ao devir, ao mais ou menos quotidiano: virtude de flexibilidade, de paciência, de dedicação, de adaptabilidade [...]"

16 "[...] este pensamento é conceitualmente rico, coerentemente organizado e persistentemente investigativo."
} 
SHARP, A. The Community of Inquiry. Education for Democracy. New Jersey:

Montclair State College, s/d.

SNYDERS, G. Alunos Felizes. São Paulo: Editora Terra e Paz, 1996.

Recebido: 25.08 .2015

Aceito: 23.11.2015

I UID/HIS/00057/2013 